lessness, heaviness, and faintness, are the chief symptoms. Indeed, as one writer observes, "chis life is choked out of him, and his sufferings are inexpressibly painful to behold, until the not unwelcome insensibility ushers in dissolution." I once saw a man stand nearly three days by the side of a chair, in the utmost distress, brought about by repeated and severe attacks of asthma; and he sank at length into a state of insensibility and death where he stood. Shorter attacks of orthopnœa as death approaches are not very rare in practice; but words are quite inadequate to describe the sufferings with which such results of asthma are attended.

3. Some diseases of the heart stand next in order for consideration.

Valvular insufficiency of whatever kind, with the exception, perhaps, of slight obstruction at the aortic orifice at an early period, alinost always leads to considerable suffering and distress, unless, indeed, the life of the patient be suddenly cut short. The circulation being impeded behind the obstructed valve, we observe irregular distribution of blood to the brain and congestion throughout the whole of the capillary system,-as that of the lungs, liver, stomach, \&c., with more or less dropsy. When these evils occur death is in propinquo, and the symptoms and effects are often very painful and harassing to the patient. He complains of pain, or a feeling of distress even worse than pain, in the region of the heart, faintness, vertigo, and headache; and, above all, distressing breathlessness, the least movement or change of posture making him pant, and gasp for life and breath, and dread instant suffocation. These effects, it will be observed, are similar to those produced by asthina, the congestion of the lungs being the same in both cases, but with this difference, that in the one case the mischief begins at the lungs, and in the other at the heart. Dropsical effusions are also common to both diseases.

Angina pectoris, another painful affection of the heart, next claims attention. It has been designated " neuralgia of the heart" by some, and was very well described by Heberden nearly a hundred years ago; and from his work, indeed, later descriptions have been chiefly borrowed; such is the case in Dr. Watson's Lectures, and also in Hooper's Vade-Mecum. In its first attack, this disease comes on when the patient is walking, especially when ascending a hill after taking food. It consists of a severe paroxysm of pain and constriction across the chest, threatening to destroy life, and obliging the sufferer immediately to stand still. The patient is apparently in health before this sudden and alarming anguish, which differs entirely from dyspncea. The pain frequently spreads from the chest to the upper part of the left arm, and even to the elbow. After the disease has lasted a year or so, the paroxysm is not terminated immediately on standing still, but persists for some time; it is also excited by slighter efforts-as riding in a carriage or on horseback, by evacuating the bowels, or by mental emotion. This spasm or fit in the region of the heart, commencing at first in walking up any ascent, especially against the wind, and afterwards excited by slighter causes, is the chief feature of the disease. But it may seize the patient when he is still, or when standing or sitting. and especially on awaking out of his first sleep, if he have been lying on his left side. Sometimes the pain spreads not only to the arm, but to the hand also, but this rarely happens; and, more rarely still, the arm is benumbed and swollen. Towards the close the attack may last many hours, keeping the patient in great agony and alarm. At length, an unusually violent fit or sudden syncope, without previous warning, terminates a wretched existence.

4. Cancer.-The last disease in this class which remains to be noticed is cancer, and I shall not dwell upon it. Cancer is still among the opprobria of surgery and medicine; for, whilst there are no internal remedies which can be said to exercise any influence over the disease, it is still sub judice whether any operative interference is justifiable, inasmuch as it may return, either in the cicatrix, in a neighbouring gland, or in an internal organ, and then run a more rapid course than before. From these facts, the subjects of this malady are very much to be pitied. They carry about with them a disease which medicine cannot reach, and for whose relief surgery can only offer the bare shadow of a hope, and not even this in all cases (as where it occurs in the uterus and rectum). Those affected by cancer suffer great pain, especially of a lancinating, neuralgic character; and sooner or later become loathsome to themselves and to all about them, if we except those angels of mercy- "few and far between"-whose affection, pity, and self-denial never fail. Since, then, this disease generally runs a fatal course, and so much needs palliatives towards its close, I have given it a place here.

(To be continued.)

\section{ON SURGICAL DRESSINGS.}

Bx T. HIRON BARTLEET, M.B., M.R.C.S., SURGEON TO THE BIRMINGHAM GBNERAL HOSPITAL.

I HAVE been for many year's increasingly disappointed with the ordinary dressings for suppurating wounds, such as amputations, excisions, burns, chronic abscesses, ulcers, \&c. ; and I believe a feeling of dissatisfaction is somewhat general. To this feeling may be attributed the great variety of dressings and of modes of dressing that have from time to time been recommended, and to it also the discarding by some of dressings altogether-the advocates of this plan recommending, for example, that a stump should be placed on a protected pillow and left altogether uncovered. Dressings have been, and still are, so frequently a harbour for dirt and decomposing discharges, that it is not surprising that their use should be less common and less complicated, or even dispensed with altogether.

Dressings usually have had some connexion with lint. Now I have found lint to be, under almost all circumstances, a useless, and very often an injurious dressing. The lint of commerce is usually prepared from calico, instead of linen, and the cotton fibre is much more irritating than that of flax-a fact which will be readily understood by comparing the two under the microscope. Lint, too, is non-absorbent to a degree that few would expect, though every surgeon must have occasionally found the flaps of an amputation or open excised breast plugged by the lint laid over it, the first few drops of discharge having gummed down its edges to the parts near.

For the application of unguents, now so seldom thought necessary, linen is much more convenient than lint, as it receives the ointment more regularly, and is less heating and bulky when applied.

I use lint myself rarely, except for two purposes : first, to check hæmorrhagic oozing, or to repress exuberant granulations, in which latter case sheet tin or lead is cleaner and more efficacious; and, secondly, for the application of lotions, where lint is useful from its sapability of containing more of the fluid than linen will do-that is, when the lint is well soaked.

Even the plan of placing the suppurating part, as a stump, on a pillow covered with india-rubber sheeting, excellent though it is in its simplicity, has its inconveniences, from the tendency of the discharge to run off the pillow on to the bedclothes. Moreover this plan cannot be carried out in cases of suppurating wounds on the trunk.

It appears to me that what is wanted is, a dressing unirritating, very absorbent, capable of retaining lotions and of being carbolised, and, for general and especially for hospital nse, of an inexpensive character and readily obtainable. I think all these requirements are found in picked oakum. In a former communication to THE LANCET I mentioned that this dressing is in frequent use among American surgeons, and that it was, I believed, first introduced into this country by my friend the late Mr. Redfern Davies. Oakum is readily to be obtained at gaols or workhouses in its crude state, in which condition it is used for caulking ships; and it is moderate in price. It consists of old ropes unpicked, and is therefore tow, but different from tow in two points: firstly, that it retains the agreeable and cleanly odour of tar, the presence of which may confer upon it some disinfecting properties; secondly, that, having been for some time twisted, when unpicked it retains a "springy" resilient condition, which renders it much more absorbent than tow. In a few words, picked oakum differs from tow just as curled borsehair differs from ordinary horsehair, and its use is in accordance with this difference.

I have been in the constant habit of using picked oakum for several years, first in the Birmingham Children's Hos- 


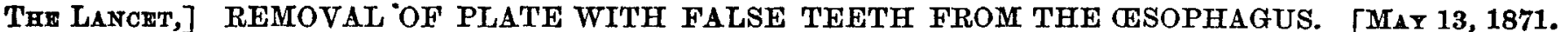

pital, and later at the General Hospital. I have used it in all kinds of suppurating wounds, and $I$ believe invariably with advantage. It is some testimong to its value that every house-surgeon who has used it has expressed to me a high opinion of it.

It may, perhaps, appear unnecessary to write about the treatment of suppurating wounds when carbolic acid is doing so much to prevent their existence. But there are always cases in hospital that cannot be treated on Lister's plan, or in which that treatment has failed, or cases that have not come under treatment until suppuration has begun. Moreover, the time and care and extra assistance required in the sealing and after-dressing of wounds by Lister's process will prevent this treatment becoming very general.

Now, of course, I do not assert that picked oakum will heal an abscess, a sinus, or an ulcer; but when such are freely suppurating I think its use will materially expedite the cure by removing the pus as rapidly as it is formed, and I also believe that the comfort of the patient will be greatly increased by its use. In any hollow wound which cannot readily be placed in a position to drain itself, it is most useful. A few months ago I removed by the trephine a portion of the frontal and parietal bones of a child, whose skull had been fractured by a kick from a horse. The dura mater was uninjured. The hollow was a few days after constantly filled with pus, which, from its lying on the dura mater, gave me some anxiety. The application of a dossil of picked oakum maintained in place by a light bandage, and reapplied night and morning, kept the cavity quite empty.

I usually treat my amputations without dressings of any kind, only placing them on a protected pillow, and first putting under them a double handful of the oakum, which absorbs the secretions and prevents them running off the macintosh on to the bed. The oakum is readily removed two or three times daily, and, by its resiliency as well as by its cleanliness, is a comfort to the patient.

In abscess of the breast, both when the patient is in bed and when she is up, a double handful of oakum placed under and on each side of the breast, and kept in position either by a light bandage or by a piece of strapping, will keep the patient dry and clean far better than any other mode of dressing I know of. I am at present dressing a private case of excision of the breast in this way, and have used no other application from the very first. In fact, in any case of suppuration, in the use of drainage tubes, and especially in deep wounds, where it is difficult to place the opening of the wound in a depending position, the oakum will be found invaluable.

I know of only one objection to its use, and that is its apparent roughness. I say apparent, because I have heard no complaints of its being irritating to a patient. I used formerly, in special cases, to place between the wound and the oakum a piece of cap-net, which either did, or at all events appeared to do, all that was required. But now the oakum is being carded by machinery, and thus prepared it is much softer than the hand-picked, while it does not seem to have at all lost its springiness or its absorbent power. I am now using some sent to the General Hospital by Messrs. Southall and Dymond, by whom it is also prepared, and I find this, which the manufacturers have named "lenax," in every way a most useful form of oakum. I think it will probably take the place of hand-picked oakum, if it can be produced sufficiently cheaply. In hospital practice, or where the expense is an object, the tenax might be used for immediate contact with the wound, while a mass of the cheaper picked oakum might be placed outside this. The ordinary hand-picked oakum may be readily procured at a cheap rate at most gaols and workhouses.

I have found so much advantage to my patients and convenience to myself from the use of this dressing that I have felt constrained to write these few remarks, to induce others to participate in the advantages which are equally important to surgeon and patient.

Birmingham, Jan, 1871.

THE "Athenæum" states that Mr. Darwin has presented to Cambridge University the remainder of the collections in invertebrate zoology made by him during the cruise of the Beagle.

\section{A CASE WHERE AN ARTIFICIAL PLATE WITH FALSE TEETH WAS SWALLOWED AND REMOVED.}

\author{
Bт JOHN MATTHEWS, M.D.
}

As a contribution to the list of "foreign bodies removed from the cesophagus," the details of the following case may prove of interest.

On the night of Sunday, March 26th last, I was called up at 1.30 A.m. to see Mrs. G. J-. The messenger only waited to say that she was choking, and ran off. On arriving at the house, I was informed that the family had been aroused by the screams of the sufferer, who was liable to frequent epileptic fits. On reaching the bedside, she was found clutching at her throat, labouring for breath, and partially unconscious, having evidently just had a severe attack. She could not swallow, nor speak much above a whisper. It was then observed that a plate holding six artificial teeth, known to be in her mouth when she went to rest, had disappeared. As it could not be found anywhere, the inference naturally arose that she had swallowed it during her fit; but of this we were uncertain, since she very often misplaced or hid articles of dress, ornaments, \&c., during the half-conscjousness succeeding her attacks.

I immediately introduced a finger as far as possible down the throat, but could feel nothing, although it reached below the glottis. The patient was so much distressed by this, that I only repeated it once with a finger of the other hand; but to no purpose, nor could any prominence be felt externally. In the absence, therefore, of absolute proof that she had swallowed the teeth, I thought it might be an aggravated case of hysteria or epileptic spasm of the pharynx; and, having prescribed accordingly, left her for a few hours, enjoining a more careful search for the missing teeth. On visiting her at 10 A.Mr. on Monday, I found matters in statu quo. She had not been able to swallow either food or medicine; but the dyspnoea was not so severe. I then explored with both fingers; but to no purpose, and left, expecting that if the plate were there it would slowly tind its way into the stomach. At 2 P.M. no alteration; teeth not found. I then proposed a consultation with $\mathrm{Mr}$. Holmes Coote; and he accordingly saw her at 6.30 P.M. He also was in considerable doubt as to whether the teeth were there or not, since he could not feel them either by the finger or a pair of long forceps which he brought with him. I may add that our efforts were seriously impeded by the strenuous resistance of the sufferer, especially with $\mathrm{Mr}$. Coote; and she finally declared that she would not suffer him to touch her any more, otherwise I have no doubt that he would have relieved her. We then left, having directed a dose of castor oil to be given in the morning.

On Tuesday morning I visited her. The castor oil ordered could not be taken, and she was still in so much distress that, after a gentle remonstrance, she promised to be more submissive to further exploration. This I attempted still with the finger, feeling sure that the obstruction was within its reach, if her description of her suffering were accurate as to place. On this occasion the left finger went further than before, reaching about an inch below the glottis (I had previously used the right finger without success); and I then had the satisfaction of feeling with my nail the edge of the plate. The patient was gasping for breath during this proceeding; I therefore removed my finger, and after a brief interval reintroduced it, sliding down at the same time, close to it, a pair of polypus forceps, by which I was able to grasp the thin edge of the plate, which was lying with its long axis transversely, its hollow closely applied to the back of the trachea, the teeth downwards. Finding it immovable except by much force, and unwilling to risk laceration of the cesophagus, after another brief interval $I$ once more insertied the left finger and forceps, grasped the plate, and then slid the forceps to its other end, so as to tilt it by the aid of the finger, when it was at once easily extracted. All the symptoms were of course immediately relieved. There was very little, in fact scarcely any, bleeding; and in two days the patient was as well as usual. 